\title{
Primeiras considerações sobre medidas aerodinâmicas da consoante nasal palatal do português brasileiro
}

\author{
First considerations on aerodynamic measurements \\ of the palatal nasal consonant of Brazilian Portuguese
}

Michele Gindri Vieira

Universidade Federal de Santa Catarina

michelegindri@gmail.com

Izabel Christine Seara

Universidade Federal de Santa Catarina

izabels@linse.ufsc.br

Resumo: Este estudo tem por objetivo investigar a consoante nasal palatal do português brasileiro $(\mathrm{PB})$, focalizando a análise acústica e as medidas aerodinâmicas obtidas a partir do piezo-elétrico. Os dados aqui discutidos referem-se à produção de três falantes naturais de Florianópolis (Santa Catarina). O piezo-elétrico, equipamento que capta as vibrações do ar nas cavidades nasais, possibilita a observação das configurações das curvas de fluxo aéreo nasal (FAN). Neste artigo, inicialmente, observase o comportamento acústico dos dados para identificação da gradiência mostrada pela consoante nasal palatal. Os resultados, por meio de análise acústica, indicam a ocorrência de uma gradiência fônica identificada nas produções que vão da consoante nasal palatal até a vogal nasalizada. Os resultados aerodinâmicos indicam distintas configurações de curvas de FAN para essas produções. Observa-se que a nasalidade mostrou-se antecipatória, com a curva de FAN iniciando antes da consoante nasal palatal; e, ao mesmo tempo, progressiva, com expansão da curva de FAN após a consoante nasal. A antecipação da curva de FAN pode ocorrer de modo variado: (1) sincronizado com o início da vogal precedente 
(antecipação total) ou (2) logo depois do início da vogal precedente (antecipação parcial). Pode-se dizer que as medidas aerodinâmicas, associadas à análise acústica, são importantes para a busca por maior entendimento da nasalidade no PB.

Palavras-chave: nasalidade; português brasileiro; consoante nasal palatal; medidas aerodinâmicas.

Abstract: This study aims to investigate the palatal nasal consonant of Brazilian Portuguese (BP), focusing on acoustic analysis and aerodynamic measurements collected with a piezoelectric sensor. The data discussed here were produced by three native speakers of BP from the city of Florianópolis (Santa Catarina). The piezoelectric sensor is a device that measures air vibrations in the nasal cavities and allows the observation of configurations for nasal air flow (NAF) curves. In this paper, the acoustic behavior of the data was initially observed to identify the gradience shown by the nasal palatal consonant. The results, through acoustic analysis, indicate the occurrence of phonic gradience identified in the productions ranging from the nasal palatal consonant to the nasalized vowel. The aerodynamic results indicate distinct NAF curve configurations for these productions. Nasality proved to be anticipatory, with the NAF curve starting before the palatal nasal consonant, while also carryover, with an increase of the NAF curve after the nasal consonant. The anticipation of the NAF curve may occur in various ways: (1) synchronized with the beginning of the previous vowel (total anticipatory) or (2) immediately after the start of the preceding vowel (partial anticipatory). It can be said that aerodynamic measures, combined with the acoustic analysis, are crucial to a greater understanding of nasality in BP.

Keywords: nasality; Brazilian Portuguese; palatal nasal consonant; aerodynamic measures.

Recebido em: 24 de outubro de 2015.

Aprovado em: 27 de junho de 2016. 


\section{Introdução}

As consoantes nasais apresentam certa complexidade para a coordenação entre a cavidade oral e nasal e dependem diretamente do funcionamento do esfíncter velofaríngeo. Essa complexidade leva à necessidade de investigações por meio tanto de análises acústicas, quanto de análises aerodinâmicas e articulatórias.

No Brasil, a caracterização acústica de consoantes nasais e de vogais nasais e nasalizadas, aliadas algumas vezes à avaliação perceptual, tem sido desenvolvida (SOUSA, 1994; SEARA, 2000; SEARA; BERRI, 2009; GAMBA, 2011; 2014). Contudo, estudos que focalizam as consoantes nasais ainda são menos aprofundados, se compararmos com os estudos realizados, principalmente, com vogais nasais. Assim, nosso objetivo é dar os primeiros passos na direção de um estudo mais completo das consoantes nasais do português brasileiro (doravante PB), iniciando com medidas aerodinâmicas da consoante nasal palatal, som de fala que tem nos instigado devido às variações que apresenta e até mesmo ao questionamento sobre sua presença no PB. Uma avaliação acústica das produções dos sujeitos pesquisados auxiliará a análise de oitiva na identificação das produções encontradas e de sua gradiência acústica.

Análises aerodinâmicas para medir o fluxo aéreo em sons nasais do PB podem ser vistas em Medeiros, D'Império e Espesser (2008); Demasi (2009); Mendonça e Seara (2015), entre outras pesquisas. Estudos aerodinâmicos com dados do francês também foram desenvolvidos por Vaissière (1995); Basset et al. (2001); Amelot (2004); Basset, Amelot e Crevier-Buchman, (2007); Brkan, Amelot e Pillot-Loiseau (2012), dentre outros.

Importante salientar que, como referido por Crowley e Bowern (2010), por se tratarem de línguas pertencentes à mesma família linguística, originárias do latim, o francês e o PB apresentam similaridades em relação à nasalidade da fala, incluindo a presença de vogais nasais, nasalizadas e de consoantes nasais. Ainda, o português e o francês apresentam nasalidade vocálica distintiva. Tendo por base essas semelhanças linguísticas, muitos estudos do francês, em relação a análises aerodinâmicas e articulatórias, foram aqui considerados.

O presente estudo tem então por objetivo introduzir uma análise qualitativa de dados aerodinâmicos referentes à consoante nasal palatal do $\mathrm{PB}$, considerando a produção na região sul do Brasil, mais 
especificamente no falar florianopolitano. Partindo-se da análise dos dados acústicos, em conjunto com a descrição do comportamento do fluxo aéreo nasal (doravante FAN), obtido por meio do piezo-elétrico, busca-se investigar as seguintes questões de pesquisa:

1) A consoante nasal palatal apresenta as mesmas características acústicas em todas as suas produções?

2) Existem configurações distintas de curvas de FAN para a consoante nasal palatal advindas do piezo-elétrico? Em caso afirmativo, elas estariam relacionadas às diferentes produções acústicas?

3) Que fenômenos de nasalidade, relacionados ao comportamento do véu do palato, ocorrem durante a produção da consoante nasal palatal: antecipação, progressão, sincronização ou atraso?

Para responder a estas questões, primeiramente serão expostas algumas considerações sobre a consoante nasal palatal [n] do PB. Na sequência, serão apresentadas suas características acústicas, articulatórias e aerodinâmicas, encontradas na literatura, enfatizando-se o papel do esfíncter velofaríngeo. Em seguida, será descrita a metodologia utilizada para a obtenção dos resultados acústicos e logo depois os aerodinâmicos. Após, serão exibidos os resultados obtidos, com base em uma análise qualitativa, relacionando os tipos acústicos e as configurações aerodinâmicas. Ao final, trataremos dos fenômenos de coarticulação da nasalidade e da conclusão do trabalho.

\section{Considerações sobre a consoante nasal palatal do PB}

O PB possui consoantes nasais, vogais nasais, vogais nasalizadas e ditongos nasais. No que se refere às consoantes nasais, são descritas três produções para o PB: uma consoante nasal bilabial [m], uma alveolar [n] e uma palatal $[\mathrm{n}]$, sendo todas vozeadas. Conforme estudos realizados por Freitas (2004) sobre o desenvolvimento das nasais, os sons nasais consonantais estão entre os primeiros a serem produzidos na fala das crianças no PB. Dentre essas consoantes, a nasal palatal tem sua aquisição mais tardia, após um ano e sete meses. Entendemos que esse fato pode estar associado à complexidade e variação encontrada na produção da consoante palatal, o que não ocorre com as demais consoantes nasais. 
As produções gradientes da consoante [n], observadas em análises de oitiva e confirmadas nas análises acústicas com falantes adultos do $\mathrm{PB}$, também podem aparecer, em maior ou menor grau, como estratégias usadas no desenvolvimento da fala das crianças.

No presente estudo, será analisada a consoante nasal palatal em ataque silábico. Nessa posição, Moraes (2013) observa que a nasalidade se propaga para a esquerda, regressivamente; para a direita, progressivamente; ou ainda para ambos os lados. Silva (2010) ainda esclarece que a consoante nasal palatal ocorre exclusivamente em posição intervocálica e a vogal precedente geralmente é nasalizada. Para Vaissière (1995), o condicionamento fonético dessa vogal precedente nasalizada, talvez universal, se deve a um fenômeno de nasalização antecipatória, resultando no abaixamento do esfíncter velofaríngeo na produção da vogal antes de uma consoante nasal. Mendonça e Seara (2015) observaram, a partir do índice de nasalização, que, no PB, as consoantes nasais intervocálicas nasalizam as vogais adjacentes tanto regressiva quanto progressivamente, conforme já apontado por Moraes (2013). As pesquisas dessas autoras indicaram também que esse índice de nasalização é dependente da consoante nasal.

Na próxima seção, serão apresentados os resultados de estudos acústicos sobre a consoante nasal palatal do PB e suas produções gradientes.

\section{Características acústicas da consoante nasal palatal do PB}

Com o propósito de buscar parâmetros para caracterizar acusticamente as produções referentes à consoante nasal palatal, apresentamos os resultados de algumas pesquisas realizadas com dados do PB.

Silva (2010) cita, como produções para essa consoante, a nasal palatal e um segmento vocálico nasalizado. As pesquisas de Sousa (1994) e de Seara (2000) também indicam a ocorrência de um segmento vocálico nasal alto anterior na produção da consoante nasal palatal. Seara (2000) analisou as ressonâncias nasais (FN1, FN2, FN3) nos contextos tônicos e átonos e observou, com certa irregularidade, duas frequências nasais que são próprias de segmentos nasais, conforme pode ser observado na Tabela 1. 
Em estudos mais recentes, na variedade florianopolitana, Gamba (2011, 2014) confirma a produção da consoante nasal palatal [n], da variante vocálica nasalizada [j] e, ainda, da síncope dessa consoante, variantes coexistentes nas produções dos três informantes pesquisados. Gamba (2011) descreve, para a consoante [n], quando o contexto vocálico precedente era a vogal baixa, o traçado de F2 como de uma abóboda, movimento de F2 semelhante ao da vogal alta. No entanto, apresentando uma região central com baixa intensidade, o que corresponderia ao bloqueio oral da consoante palatal. Para a produção [j], o padrão formântico foi caracterizado por F2 não se aproximar de F3, e ainda, por F2 apresentar uma subida mais moderada, ao invés do formato de abóboda descrito para a consoante.

De modo qualitativo, Gamba (2014) descreve o traçado dos formantes da consoante nasal palatal. Indicou o F1 entre 250 e 330 $\mathrm{Hz}$, com uma queda da frequência no centro e subida no final para a vogal seguinte; F2 iniciando-se alto (após subida na vogal precedente), mantendo-se estável ao longo do percurso e aproximando-se de F3; e com queda no final. Observe também na Tabela 1 a distribuição de valores médios obtidos nos estudos de Gamba $(2011,2014)$.

\section{TABELA 1}

Valores frequenciais dos formantes nasais da consoante nasal palatal encontrados em estudos do PB.

\begin{tabular}{c|c|c|c}
\hline Formantes nasais & Seara (2000) & Gamba (2011) & Gamba (2014) \\
\hline FN1 & $252-268 \mathrm{~Hz}$ & $357 \mathrm{~Hz}$ & $250-330 \mathrm{~Hz}$ \\
\hline FN2 & $1014-1025 \mathrm{~Hz}$ & $1992 \mathrm{~Hz}$ & --- \\
\hline FN3 & $2182-2248 \mathrm{~Hz}$ & $2888 \mathrm{~Hz}$ & --- \\
\hline
\end{tabular}

FONTE: Adaptado de Seara (2000) e de Gamba (2011, 2014).

Fant (1960), para sons nasais, se refere a formantes nasais (FN) razoavelmente fixos em $250 \mathrm{~Hz}$ (FN1), $1000 \mathrm{~Hz}$ (FN2), $2000 \mathrm{~Hz}$ (FN3), $3000 \mathrm{~Hz}$ (FN4) e $4000 \mathrm{~Hz}$ (FN5). Porém, segundo o autor, o formante nasal em $1000 \mathrm{~Hz}$ nem sempre está acima do limite de detectabilidade em espectrogramas devido a sua baixa intensidade. Daí a sua irregularidade em diversos estudos, como, por exemplo, nos de Gamba (2011) e Seara (2000). 
Dados de consoantes nasais, como os exibidos em Seara (2000), indicam que o FN2 em torno de $1000 \mathrm{~Hz}$ pode ser ou não detectado nesses sons consonantais. No estudo de House e Stevens (1957), o FN1 das consoantes nasais apresenta-se em torno de 200 a $300 \mathrm{~Hz}$ e o FN2 está presente com valores em torno de $1000 \mathrm{~Hz}$. A indicação de FN2 também foi variada nos dados apontados por Sousa (1994) para as consoantes nasais [m] e [n] do PB. A autora menciona que o FN2 apresentou inúmeras irregularidades e nem sempre era possível ser detectado (ou seja, seu efeito era provavelmente atenuado ou anulado pelo efeito de um antiformante na mesma região de frequência), sendo que os únicos formantes que ocorreram em todas as elocuções foram FN1 e FN3. Esses dados corroboram o exposto por Fant (1960). Na vogal nasal alta anterior, similarmente à consoante nasal, o FN2 também pode estar presente. Isso se deve ao acoplamento das cavidades oral e nasal e a consequente modificação no espectro acústico, com o aparecimento de formantes nasais em baixas frequências. Ao examinar a distribuição frequencial da vogal nasal alta anterior, Seara (2000) aponta a ocorrência de um formante em torno de $1000 \mathrm{~Hz}$, que foi considerado como um formante nasal (FN2), pois a vogal oral alta anterior exibe tradicionalmente dois formantes orais, o primeiro em torno de $300 \mathrm{~Hz}$ e o segundo em torno de $2000 \mathrm{~Hz}{ }^{1}$

$\mathrm{Na}$ Seção 3, será evidenciada a relação entre a nasalidade e o esfíncter velofaríngeo.

\section{O esfíncter velofaríngeo e a nasalidade}

Altmann (2007) esclarece que o esfíncter velofaríngeo é formado anatomicamente pelo véu do palato e pelas paredes da faringe. Funcionalmente, na fala, o véu do palato passa da posição de repouso, quando está elevado, para o movimento de abertura ou abaixamento. O contraste entre sons orais e nasais é estabelecido pelo movimento do esfíncter velofaríngeo, que controla a presença e o grau de acoplamento entre as cavidades oral e nasal para a produção das vogais e consoantes (VAISSIÈRE, 1995).

\footnotetext{
${ }^{1}$ A autora não referiu em sua pesquisa, se na fala dos participantes havia formante de traqueia, porém não se pode descartar essa possibilidade.
} 
Em nível articulatório, um dos pontos para a diferenciação entre vogais nasais e consoantes nasais pode ser entendido a partir da liberação do fluxo de ar pulmonar. Enquanto, nas vogais nasais, não há nenhum impedimento à passagem do fluxo aéreo no trato vocal (cavidades oral e nasal), para as consoantes nasais, há uma obstrução total e momentânea do fluxo de ar na cavidade oral, havendo quase ao mesmo tempo a liberação do ar pela cavidade nasal com o movimento do esfíncter velofaríngeo, que permanece aberto (SEARA; NUNES; LAZZAROTTO-VOLCẪO, 2015). Devido à passagem de ar sem impedimento, a produção da vogal exibe ressonâncias com mais amplitude do que a produção da consoante nasal, que, por apresentar um bloqueio, é emitida com uma atenuação geral da amplitude das ressonâncias (KELLER, 1999).

$\mathrm{Na}$ produção da vogal nasal [1], a língua movimenta-se para frente, colocando-se em posição alta, sem contato com o palato duro (SEARA; NUNES; LAZZAROTTO-VOLCÃO, 2015). No caso da consoante nasal palatal [n], Silva (2010) explica que há um bloqueio na cavidade oral realizado pelo movimento da língua na região do palato duro. Observa-se similaridade nos movimentos realizados pela língua, tanto para essa vogal nasal quanto para a consoante nasal palatal.

Um aspecto sugerido por Bell-Berti (1993) para diferenciar a vogal nasal alta da consoante nasal é o grau de abaixamento do véu do palato em função da altura da língua na produção vocálica. Assim, o véu seria mais abaixado na produção de consoantes nasais e menos abaixado para as vogais altas orais. Segundo a autora, o menor abaixamento do véu do palato deve-se, provavelmente, à posição da língua estar bastante alta na produção dessas vogais.

Na seção seguinte, serão apresentadas análises aerodinâmicas utilizadas no estudo do fenômeno coarticulatório da nasalidade.

\section{Análises aerodinâmicas da nasalidade a partir do piezo-elétrico}

As técnicas utilizadas para investigar a nasalidade da fala estão relacionadas ao movimento do esfíncter velofaríngeo para o acoplamento das cavidades oral e nasal. Por isso um grande número de estudos tem pesquisado aspectos fisiológicos, acústicos e aerodinâmicos do mecanismo velofaríngeo no seu aspecto funcional, durante a fala.

Vaissière (1995) desenvolve estudos aerodinâmicos e destaca procedimentos não invasivos, como o uso do captador piezo-elétrico e 
do microfone nasal, que permitem inferir sobre os movimentos do véu do palato. Além desses, o microfone oral é utilizado para o registro de dados acústicos. Esses equipamentos são exibidos na Figura 1.

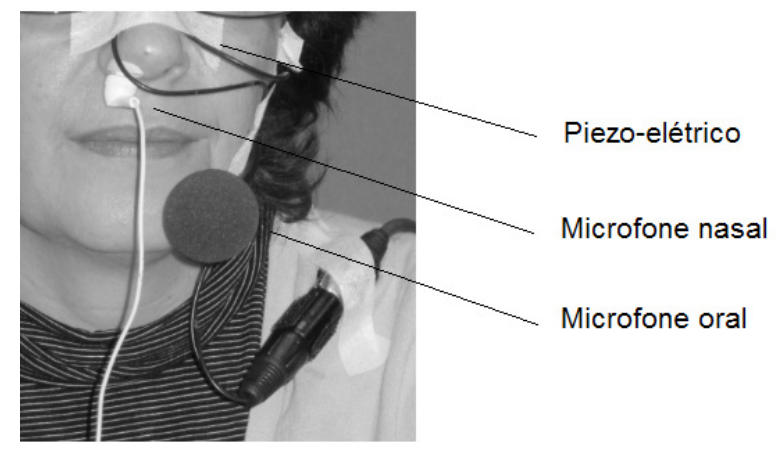

FIGURA 1 - Equipamentos utilizados para estudos acústicos e aerodinâmicos: piezo-elétrico, microfone nasal e microfone oral.

FONTE: arquivo pessoal da autora. Divulgação de imagem autorizada.

No presente estudo, focalizaremos as análises aerodinâmicas obtidas a partir do captador piezo-elétrico. O captador piezo-elétrico tem sido usado para estudos dos fenômenos da nasalidade (BRKAN; AMELOT; PILLOT-LOISEAU, 2012) com a finalidade de converter a energia mecânica (movimento vibratório) em sinais elétricos (FERNANDES, 2000). Os sinais de vibração consistem geralmente de inúmeras frequências que ocorrem simultaneamente. Com a utilização da técnica de análise de frequência é possível relacionar a amplitude do sinal com a sua respectiva frequência. Uma das maneiras pela qual a amplitude da vibração pode ser quantificada é o nível quadrático médio (ou RMS - Root Mean Square), que é uma importante medida de amplitude porque mostra a média da energia contida no movimento vibratório (FERNANDES, 2000; MARQUES, 2007). O piezo-elétrico é afixado na superfície externa do nariz e registra a amplitude das vibrações do fluxo de ar nas cavidades nasais quando ocorre a ressonância nasal (VAISSIĖRE et al., 2010). Observe na Figura 1 o microfone captador do sinal acústico nasal utilizado em conjunto com o microfone captador do sinal acústico oral, que servem para medir a pressão sonora. 
Serão descritos a seguir alguns estudos, baseados em especial sobre análises aerodinâmicas, incluindo os que tratam da nasalidade do $\mathrm{PB}$ e do francês.

\section{Estudos aerodinâmicos da nasalidade}

Vaissière (1995) aponta que os aspectos aerodinâmicos estão relacionados com a forma da cavidade oral para produção das consoantes nasais e que dependem do ponto de articulação (bilabial, alveolar, palatal), do contexto vocálico vizinho à consoante e das características acústicas consonantais.

Para o francês, Vaissière (1995) observou o papel do movimento do esfíncter velofaríngeo no curso temporal da fala, a partir de estudos aerodinâmicos e articulatórios. A autora constatou que o véu do palato está geralmente elevado durante a fala, sendo abaixado temporariamente na presença de um som nasal. Sobre a altura do véu do palato, a autora encontrou fatores que a influenciam: (i) o fenômeno de antecipação do abaixamento do véu do palato durante a emissão da vogal que precede a consoante nasal; e (ii) o fenômeno de nasalização progressiva, ou seja, quando a nasalidade se propaga à direita para outras vogais.

A maior parte dos estudos aerodinâmicos é realizado com sons vocálicos nasais e com a estação aerodinâmica EVA2 ${ }^{\mathrm{TM}}$ (Evaluation Vocale Assistée, SQLab), empregada para avaliar os parâmetros de fluxo de ar nasal (dados que são semelhantes aos obtidos pelo piezo-elétrico) e fluxo de ar oral. Nesse caso, como no presente estudo, são utilizadas medidas sincronizadas de dados acústicos e aerodinâmicos. Assim, a seguir, apresentaremos os principais resultados que podem ser associados aos dados tratados no presente estudo.

Basset et al. (2001) esclarecem que a presença do fluxo aéreo nasal indica que a porta velofaríngea está aberta, mas a ausência de FAN não significa que a porta velofaríngea esteja fechada, uma vez que, para a produção de uma vogal ou consoante nasal, a abertura velofaríngea está entre $0,4 \mathrm{e} 1,0 \mathrm{~cm}^{2} \mathrm{e}$ assim com uma abertura menor não haveria passagem de ar pelas cavidades nasais (AMELOT, 2004). Para um entendimento mais exato referente à abertura ou ao fechamento velofaríngeo, seria necessária uma análise articulatória. Basset et al. (2001), no entanto, analisaram somente medidas aerodinâmicas da nasalidade das vogais a partir da produção de quatro falantes nativos do francês. Eles também 
utilizaram a estação EVA2 e compararam os fenômenos de movimento do véu do palato durante a produção de fala espontânea e de fala lida. Os autores definem como antecipação (antecipation) quando o FAN começa antes do surgimento da nasal; atraso (delay) quando o FAN começa após o início da vogal nasal e; progressivo (carryover) quando o FAN se espalha sobre o segmento seguinte. Citam, ainda, a possibilidade de ocorrer o início e o final da curva de FAN sincronizados (synchronous), com a produção do som nasal. Os resultados mostraram uma tendência da curva de FAN iniciar antes da vogal nasal (51 a 54\%) e uma forte propensão para se estender depois da nasal (89 a 94\%).

Basset, Amelot e Crevier-Buchman (2007) estudaram as consoantes nasais $[\mathrm{m}, \mathrm{n}]$ do francês por meio de medidas aerodinâmicas, obtidas com a estação EVA2, e com medidas articulatórias, obtidas com a nasofibroscopia, com três falantes nativos do francês. Os resultados mostraram uma diferença de duração, dependendo do tipo de dado (acústico, aerodinâmico ou articulatório), sendo que a duração do ciclo de abaixamento do véu (articulatório) é o mais longo, seguido pela duração do FAN (aerodinâmico), que é maior do que a duração dos segmentos acústicos correspondentes às consoantes nasais. A propagação do movimento velar é tanto progressiva quanto regressiva, enquanto a propagação do fluxo de ar nasal é bastante gradual.

Medeiros, D'Imperio e Espesser (2008) pesquisaram dados aerodinâmicos (fluxo de ar nasal e oral), utilizando o EVA2, com cinco falantes do PB do sudeste do Brasil. Analisaram o murmúrio nasal das vogais nasais (denominado de apêndice nasal) diante de dois contextos segmentais diferentes: antes de [p] (contexto oclusivo - 'quimpa') e antes de [f] (contexto fricativo - 'canfa'). As autoras consideraram o apêndice nasal, que apresenta elevado nível de fluxo de ar nasal, como resultante da constelação de gestos implicados na produção de uma sequência vogal nasal + consoante oral: gesto vocálico, velar e labial. O gesto velar seria ativado durante o gesto vocálico e se sobreporia ao labial, sendo altamente sensível à altura vocálica e aos contextos adjacentes.

Mendonça e Seara (2015), em estudo sobre as vogais nasalizadas coarticulatoriamente, tendo por base dados de dois falantes florianopolitanos, obtidos com o piezo-elétrico, verificaram que todas as três consoantes nasais do PB exerceram efeitos coarticulatórios sobre as vogais [a], [e], [i], [o] e [u]. Foram utilizados logatomas, nos quais as consoantes nasais ocupavam contextos tônicos e átonos (postônicos). 
As autoras sugeriram uma diferença no surgimento do FAN entre as consoantes nasais do $\mathrm{PB}$, de modo que o FAN para a produção [m] iniciou-se muito próximo do onset desse segmento, mostrando pouca antecipação sobre a vogal antecedente; o FAN para a produção do [n] apresentou antecipação moderada, e em [n] o FAN foi o mais antecipado, se comparado com as duas outras consoantes nasais.

Passemos agora à metodologia empregada no presente estudo sobre aspectos acústicos e aerodinâmicos da produção da consoante nasal palatal no $\mathrm{PB}$.

\section{Metodologia}

Esta pesquisa está vinculada ao Laboratório de Fonética Aplicada (FONAPLI) e ao Programa de Pós-Graduação em Linguística, da Universidade Federal de Santa Catarina (UFSC), situados em Florianópolis/Brasil. Foi aprovada pelo Comitê de Ética em Pesquisa com Seres Humanos (CEPSH) da UFSC sob o número de processo 2057, FR 434924.

Os dados acústicos e aerodinâmicos analisados no presente estudo constituem-se em uma pequena amostra do banco de dados referente à nasalidade das vogais do PB, do projeto "O Detalhe Fonético: análise acústica exploratória de segmentos de fala", do FONAPLI. Esses dados foram coletados no Laboratoire de Phonétique et Phonologie, da Université Paris III - Sorbonne Nouvelle, em Paris/França, no ano de 2011.

\subsection{Participantes}

Foram coletados dados de três falantes nativos do $\mathrm{PB}$, do sexo feminino, nascidos e residentes na cidade de Florianópolis/SC/Brasil, com idades entre 25 e 52 anos, nível de escolaridade superior e denominados locutor 1 (L1), locutor 2 (L2) e locutor 3 (L3). No período de gravação, esses informantes se encontravam em Paris e autorizaram suas participações mediante o Termo de Consentimento Livre e Esclarecido. Os participantes não apresentavam alteração de fala e de linguagem em suas histórias pregressas ou no momento da coleta. 


\subsection{Corpus}

O corpus utilizado para as gravações incluiu pares de logatomas que continham como alvo a consoante nasal palatal. No primeiro logatoma do par, o alvo está em contexto átono (postônico) e, no segundo, em contexto tônico. Os logatomas estão dispostos na seguinte fraseveículo: 'Digo baixinho' (por exemplo: 'Digo papanha panhapa baixinho'), conforme mostrado na Tabela 2.

\section{TABELA 2}

Corpus contendo frases-veículo e os pares de logatomas com a consoante nasal palatal do PB.

\begin{tabular}{ll}
\hline \multicolumn{2}{c}{ Consoante nasal palatal [n] } \\
\hline Contexto tônico & Contexto átono \\
\hline Digo papanha & panhapa baixinho. \\
Digo papenha & penhapa baixinho. \\
Digo papinha & pinhapa baixinho. \\
Digo paponha & ponhapa baixinho. \\
Digo papunha & punhapa baixinho. \\
\hline
\end{tabular}

FONTE: primária (2015).

Os logatomas (por exemplo: papanha-panhapa) são estruturados com $\mathrm{CV}^{\prime} \mathrm{CV}_{1} \mathbf{C n V}_{2}-\mathrm{CV}_{1}{ }^{\prime} \mathbf{C n V} \mathbf{V}_{2} \mathrm{CV}$, em que $\mathbf{C n}$ é a consoante nasal [n] intervocálica e está na posição de onset, $\mathbf{V}_{1}$ é a vogal precedente e $\mathbf{V}_{2}$, a vogal seguinte. Em ambos os contextos de tonicidade, o som que precede a consoante nasal é formado por cinco vogais nasalizadas do

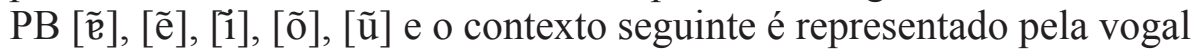
baixa átona $[\mathrm{e}]$.

Considerando-se os três locutores, os cinco contextos precedentes, os dois contextos de tonicidade, inseridos na frase-veículo, as gravações dos dados corresponderam ao total de 30 produções da consoante nasal palatal $(3 \times 5 \times 2)$. Como o número de dados ainda é muito pequeno, a análise acústica aqui apresentada servirá somente para uma comparação qualitativa com dados de outros estudos, permitindo um olhar sobre a gradiência do comportamento acústico exibida por essa consoante e para auxiliar nas observações de cunho aerodinâmico. Uma investigação mais ampla desses resultados será tema de futuras pesquisas. 


\subsection{Coleta dos dados}

Os equipamentos utilizados para a coleta das gravações dos dados acústicos e aerodinâmicos, de modo simultâneo, foram o microfone oral e o captador piezo-elétrico, conforme ilustrados na Figura 1.

O captador piezo-elétrico ( $K \& K$ Sound) é acoplado ao nariz por meio de duas pastilhas do diâmetro de $0,5 \mathrm{~cm}$, fixadas por um adesivo de dupla face nos ossos aterais do nariz (LIPPMAN, 1981 apud BRKAN; AMELOT; PILLOT-LOISEAU, 2012). Ele está ligado a um préamplificador (40dB) e a uma placa de aquisição externa (Motu UltraLite $m k 3$ hybride). A medida do piezo-elétrico é feita com base em uma referência. Essas medidas de nasalidade são transformadas em percentuais em relação a essa referência que é tomada de palavras usadas para calibração do equipamento na gravação de cada participante e obtenção do valor máximo de RMS. Esse valor máximo é obtido com base na

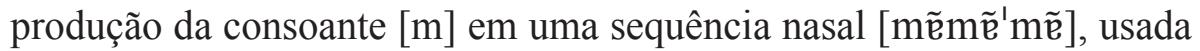
na calibração. Assim 100\% de nasalidade seria referente ao valor máximo para essa consoante. O microfone captador do sinal acústico oral é apoiado nas orelhas e capta o sinal da gravação dos dados com posição e distância fixas da boca do falante. É um microfone do tipo MicroMic C520L. Observe as posições dos dispositivos na Figura 1. A coleta dos dados acústicos e aerodinâmicos foi realizada em uma sala com tratamento acústico.

Os dados acústicos obtidos pelo microfone oral foram segmentados e etiquetados por análise visual dos dados com o uso do software Praat (BOERSMA; WEENINK, 2011). Na sequência, esses dados foram sincronizados através de um script (AMELOT, 2011) que faz a interface entre diferentes softwares (Praat; MATLAB ${ }^{2}$ ) para a obtenção da visualização das medidas a partir dos valores de RMS dos sinais nasais obtidos com o piezo-elétrico. Dessa forma, pôde-se verificar o aspecto aerodinâmico das consoantes nasais e seus contextos vocálicos, precedentes e seguintes. O script gera então uma tabela com os valores de RMS do piezo-elétrico do ponto inicial, medial e final de etiquetagem do som e ainda o valor médio de RMS.

Um exemplo dos dados acústicos e aerodinâmicos analisados é apresentado na Figura 2. Os dados são exibidos em duas janelas, sendo o eixo x representado pelo tempo e o eixo y pela amplitude do sinal. Na janela (a), é mostrado o sinal acústico com a forma de onda e a

\footnotetext{
${ }^{2}$ MATLAB - Disponível em <http://www.mathworks.com/products/matlab/>.
} 
etiquetagem de cada segmento que compõe os logatomas. Nessa figura, tem-se o exemplo do par de logatomas: papanha panhapa. Na janela (b), são apresentados os dados aerodinâmicos obtidos com o piezo-elétrico (RMS piezo). A curva de FAN pode ser quantificada pelos valores de RMS.

a)

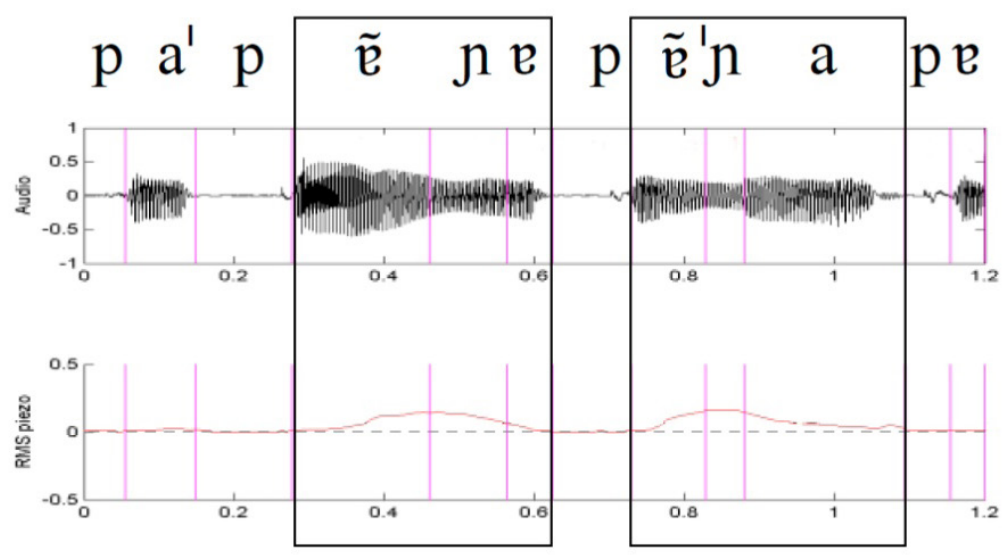

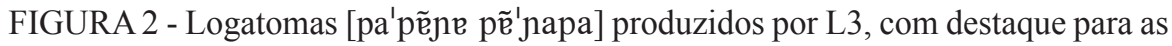

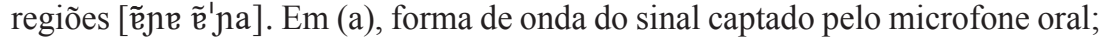
em (b), curvas de RMS do fluxo de ar nasal (FAN) captado pelo piezo-elétrico.

FONTE: primária (2015).

\subsection{Procedimentos de análise}

Os dados acústicos referentes à consoante nasal palatal foram analisados com o software Praat, a partir da percepção auditiva, da amplitude da forma de onda, do espectrograma, considerando os traçados dos formantes e suas respectivas intensidades (energia formântica). Foi realizada reamostragem do sinal de fala ao dobro da freqüência máxima de $5000 \mathrm{~Hz}$. Também foram consideradas as medidas espectrais, extraídas por meio de análises Fast Fourier Transform (FFT) e suavização cepstral (Cepstral smoothing). A partir da seleção de quatro pulsos glotais na região medial do som correspondente à consoante nasal palatal, foi realizada uma superposição do espectro de Fourier de banda estreita (janela de 0,025 s) e do cepstro com filtragem de até $500 \mathrm{~Hz}$. Dessa forma, foi possível analisar os picos das curvas (regiões formânticas) e obter os valores das frequências dos formantes (To Spectrum Tier peaks). Essas análises podem ser visualizadas na Figura 3. 
a)

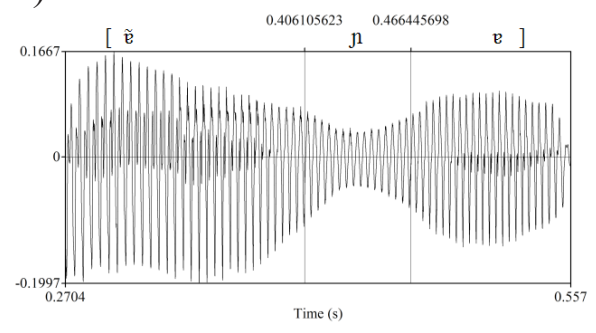

c)

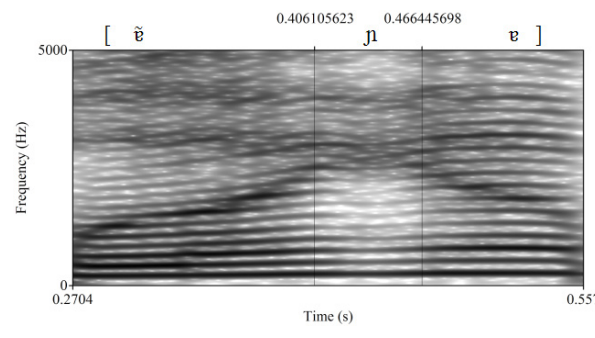

b)

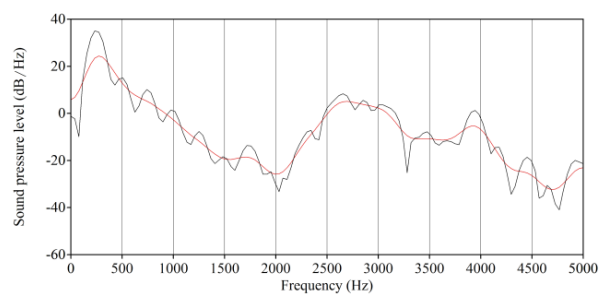

d)

\begin{tabular}{|c|c|c|}
\hline formantes & freq(Hz) & pow $(\mathrm{dB} / \mathrm{Hz})$ \\
\hline 1 & 276 & 24,37 \\
\hline 2 & 1705 & $-18,45$ \\
\hline 3 & 2693 & 5,09 \\
\hline 4 & 3466 & $-10,70$ \\
\hline 5 & 3925 & $-5,27$ \\
\hline
\end{tabular}

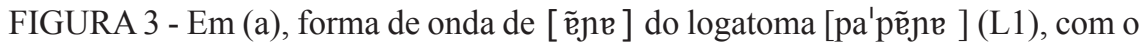
som-alvo delimitado pelo pontilhado; em (b), espectrograma com traçados e energia dos formantes; em (c), superposição do espectro FFT de banda estreita com janela de $0,025 \mathrm{~s}$ (preto) e cepstro (vermelho), em (d), frequências dos formantes do som-alvo. FONTE: primária (2015).

Em seguida, foram analisados os dados aerodinâmicos buscandose um padrão para sua ocorrência. O software Ocenaudio, versão 2.0.13 (build 6997) ${ }^{3}$, também foi utilizado para visualização em paralelo das formas de onda das medidas obtidas pelo microfone oral e pelo piezoelétrico, conforme Figura 4. Possibilitou, assim, comparar o sinal acústico da vogal precedente, da consoante nasal e da vogal seguinte, com o início e o final das vibrações captadas na passagem do fluxo de ar nasal (FAN) para uma melhor análise da antecipação da nasalidade.

${ }^{3}$ Desenvolvido pelo grupo de pesquisa do Laboratório de Circuitos e Processamento de Sinais (LINSE) da Universidade Federal de Santa Catarina. Disponível em http:// www.ocenaudio.com.br/. 
a)

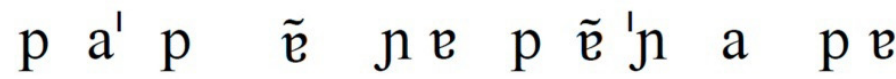

b)

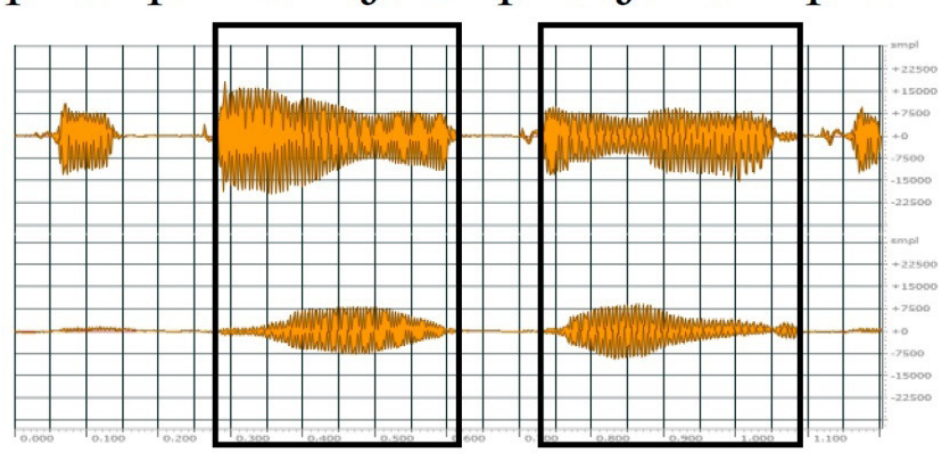

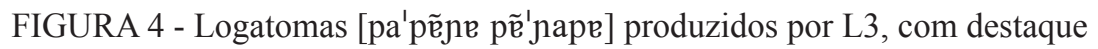

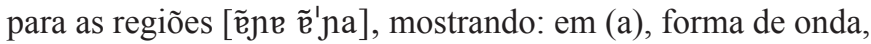
captada pelo microfone oral (sinal acústico) e, em (b), forma de onda do FAN, captada pelo piezo-elétrico (vibração).

FONTE: primária (2015).

\section{Resultados e discussão}

\subsection{Análise acústica}

Iniciamos a apresentação dos resultados obtidos por meio da análise acústica dos sons nasais palatais intervocálicos, representados pelo grafema 'nh' nos logatomas do corpus da pesquisa (Tabela 2).

Buscamos conciliar uma avaliação perceptual auditiva com a análise acústica para decidirmos sobre a classificação apresentada pelos sons nasais palatais. Inicialmente ouvimos as produções de todo o logatoma, depois, da região $\mathrm{V}_{1} \mathrm{CnV}_{2}$ e, em seguida, somente da região $\mathrm{Cn}$. O objetivo era buscar padrões classificatórios, no entanto não conseguimos de oitiva tal classificação. Na sequência, observamos a amplitude da forma de onda, esperando maior amplitude para a vogal e menor para a consoante. A amplitude da forma de onda, por apresentar muitas irregularidades nos dados, não auxiliou na identificação das produções consonantais e vocálicas.

Depois, avaliamos o traçado e a intensidade dos formantes do som nasal visualizados no espectrograma. Esperava-se maior energia 
formântica, com escurecimento na região entre a vogal precedente $\left(\mathrm{V}_{1}\right)$ e a vogal seguinte $\left(\mathrm{V}_{2}\right)$, na produção do som vocálico nasalizado. Todavia, para a consoante, buscava-se uma redução da intensidade, com clareamento na região do som nasal, relacionando esse fenômeno ao bloqueio do fluxo de ar na cavidade oral, característico das consoantes. A análise espectrográfica contribuiu para a classificação dos dados em produções com características consonantais e vocálicas.

As curvas obtidas com a superposição das análises espectrais (FFT e cepstral) mostraram-se bastante consistentes para diferenciar as produções: consonantais e vocálicas. Entretanto, a análise das frequências dos formantes listadas não indicou um padrão que diferenciasse precisamente produções consonantais e vocálicas, uma vez que houve a detecção de um formante em torno de $1000 \mathrm{~Hz}$ para ambos os tipos de produções classificadas. Por isso, os valores das frequências dos formantes serão analisados posteriormente para auxiliar na caracterização dos tipos acústicos, após sua classificação.

Então, foram consideradas, de modo associado, as classificações das análises espectrográficas e espectrais, sendo possível classificar 18 dos 30 dados em [n] ou [j]. Observamos que, dos 12 dados restantes, alguns tendiam mais para características vocálicas (espectrograma: maior intensidade na região do som-alvo em F2 e F3; análises espectrais: maior amplitude nas frequências mais altas), enquanto outros, mais para características consonantais (espectrograma: menor intensidade na região do som-alvo em FN2 e FN3; análises espectrais: perda de amplitude nas frequências mais altas), mas de forma menos evidente do que nos 18 dados anteriores.

Portanto, os critérios das análises espectrais somados à análise da intensidade (escurecimento e clareamento) no espectrograma foram os mais fidedignos para a identificação das produções encontradas. As análises acústicas realizadas permitiram a observação da gradiência dos sons-alvo caracterizando o contínuo que vai da produção de uma consoante nasal palatal até a produção de um som vocálico nasalizado, além da descrição acústica dos dados que mostravam mais características consonantais ou vocálicas.

Após a análise dos parâmetros acústicos, foi estabelecida uma classificação dos dados nasais, com a identificação de quatro tipos de produções acústicas: 1) consonantal $(n=10)$; 2) características mais consonantais $(n=6) ; 3)$ características mais vocálicas $(n=6)$; e 4) vocálico 
$(n=8)$. Na Figura 5, estão exemplificados os tipos acústicos classificados, com (a) espectrograma e com (b) superposição do espectro de Fourier de banda estreita com janela de $0,025 \mathrm{~s}$ (preto) e cepstro (vermelho) com filtragem de até $500 \mathrm{~Hz}$ para a região medial do som correspondente à consoante nasal palatal dos logatomas inseridos na frase-veículo "Digo baixinho.", emitidos pelos locutores florianopolitanos.

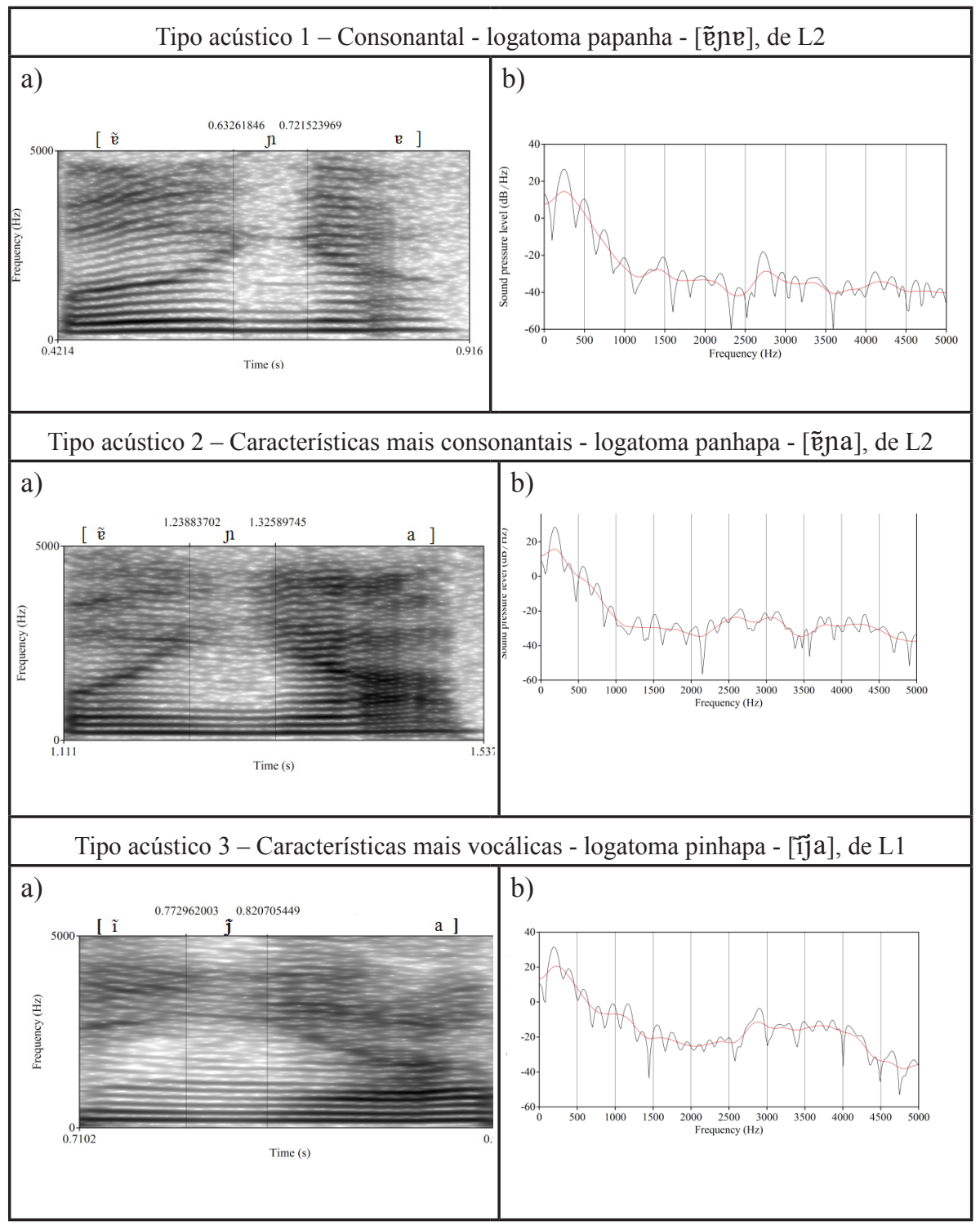




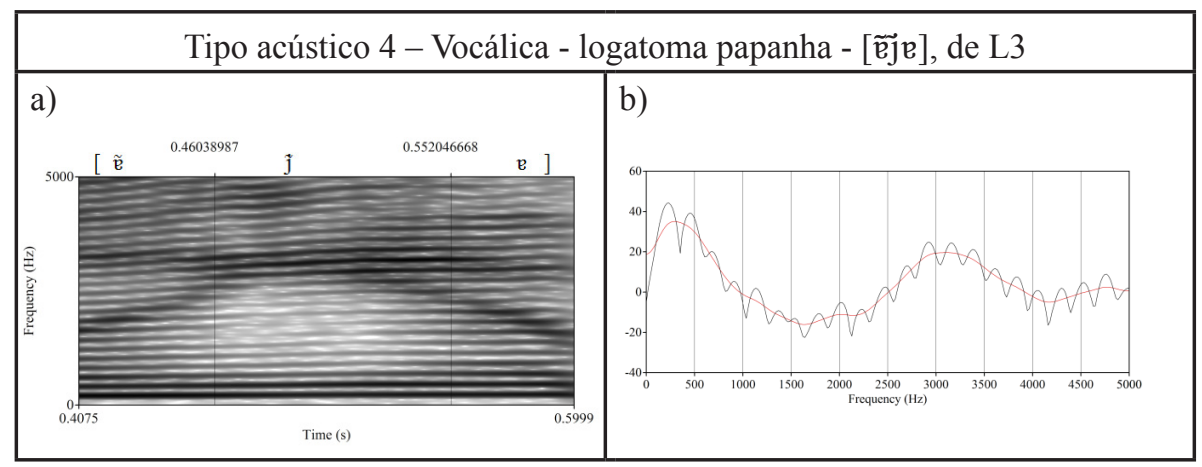

FIGURA 5 - Exemplos de tipos de produções: Tipo Acústico 1: consonantal;

Tipo Acústico 2: características mais consonantais. Tipo Acústico 3: características mais vocálicas; Tipo Acústico 4: vocálico. Em (a), espectrograma e, em (b), superposição do espectro de Fourier de banda estreita com janela de $0,025 \mathrm{~s}$ (preto) e cepstro (vermelho).

FONTE: primária (2015).

Na Tabela 3, estão descritas as características dos parâmetros analisados para a classificação acústica: intensidade dos formantes no espectrograma (clareamento e escurecimento da energia formântica); superposição do espectro de Fourier e cepstro; detecção do segundo formante nasal (FN2) em torno de $1000 \mathrm{~Hz}$, ocorrendo entre 900 e $1600 \mathrm{~Hz}$. 


\section{TABELA 3}

Caracterização dos parâmetros (intensidade dos formantes no espectrograma; espectro FFT e cepstro; detecção de formante em torno de $1000 \mathrm{~Hz}$ ) verificados por tipos de produções: Tipo Acústico 1: consonantal, Tipo Acústico 2: características mais consonantais, Tipo Acústico 3: características mais vocálicas e Tipo Acústico 4: vocálico.

\begin{tabular}{|c|c|c|c|}
\hline $\begin{array}{c}\text { Tipo } \\
\text { Acústico }\end{array}$ & $\begin{array}{l}\text { Intensidade dos } \\
\text { formantes }\end{array}$ & Espectro FFT e cepstro & Formantes (FN2) \\
\hline 1 & $\begin{array}{l}\text { Redução de } \\
\text { intensidade, entre } \mathrm{V}_{1} \mathrm{e} \\
\mathrm{V}_{2} \text {, com clareamento } \\
\text { evidente em toda a } \\
\text { extensão do som-alvo }\end{array}$ & $\begin{array}{l}\text { Evidente perda } \\
\text { de amplitude nas } \\
\text { frequências mais altas }\end{array}$ & $\begin{array}{l}\text { Detecção de FN2 em } \\
\text { torno de } 1000 \mathrm{~Hz} \text { em } \\
\text { todos os dados }\end{array}$ \\
\hline 2 & $\begin{array}{l}\text { Redução de } \\
\text { intensidade na } \\
\text { região entre } \mathrm{V}_{1} \mathrm{e} \\
\mathrm{V}_{2} \text {, no entanto } \\
\text { mais escurecida se } \\
\text { comparada àquela } \\
\text { apresentada no Tipo } \\
\text { Acústico } 1\end{array}$ & $\begin{array}{l}\text { Evidente perda } \\
\text { de amplitude nas } \\
\text { frequências mais altas }\end{array}$ & $\begin{array}{l}\text { Detecção de FN2 em } \\
\text { torno de } 1000 \mathrm{~Hz} \text { na } \\
\text { maioria dos dados }\end{array}$ \\
\hline 3 & $\begin{array}{l}\text { Mantém a intensidade } \\
\text { na região entre } V_{1} \\
\text { e } V_{2} \text {, porém menos } \\
\text { escurecida se } \\
\text { comparada àquela } \\
\text { apresentada no Tipo } \\
\text { Acústico } 4\end{array}$ & $\begin{array}{l}\text { Apresenta maior } \\
\text { amplitude nas } \\
\text { frequências mais altas }\end{array}$ & $\begin{array}{l}\text { Detecção de FN2 em } \\
\text { torno de } 1000 \mathrm{~Hz} \text { na } \\
\text { maioria dos dados }\end{array}$ \\
\hline 4 & $\begin{array}{l}\text { Mantém a intensidade } \\
\text { na região entre } \\
\mathrm{V}_{1} \text { e } \mathrm{V}_{2} \text {, com } \\
\text { escurecimento } \\
\text { evidente nessa região }\end{array}$ & $\begin{array}{l}\text { Apresenta maior } \\
\text { amplitude nas } \\
\text { frequências mais altas }\end{array}$ & $\begin{array}{l}\text { FN2 em torno de } 1000 \\
\text { Hz não detectado na } \\
\text { maioria dos dados }\end{array}$ \\
\hline
\end{tabular}

FONTE: primária (2015).

Estes quatro tipos principais de ocorrência comprovam a existência da consoante nasal palatal (Tipo Acústico 1) no dialeto de Florianópolis e por consequência, no PB. Demonstram, ainda, que esse som nasal apresenta, além de sua produção vocálica nasalizada (Tipo Acústico 4), também indicada em estudos anteriores, outras produções 
com características similares à consoante (Tipo Acústico 2) ou à vogal (Tipo Acústico 3). Essas variações no detalhe acústico podem ser vistas como uma gradiência, com um contínuo de possíveis produções entre as categorias de consoante e de vogal, como esquematizado na Figura 6.

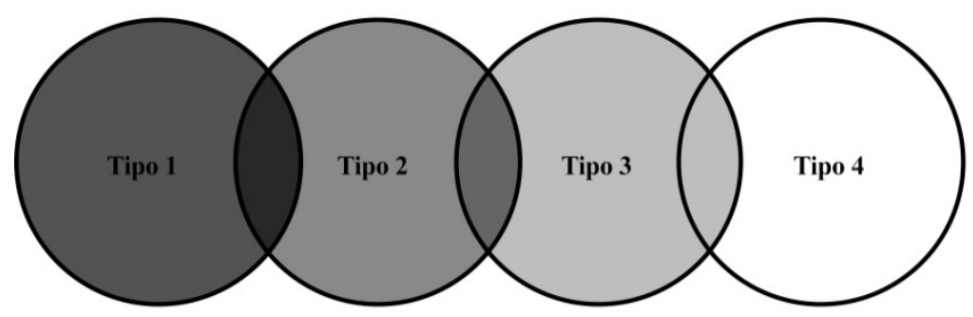

FIGURA 6 - Representação da gradiência encontrada na produção da consoante nasal palatal do $\mathrm{PB}$, com base na produção de três locutores de Florianópolis/SC/Brasil. Tipo Acústico 1: consonantal; Tipo Acústico 2: características mais consonantais;

Tipo Acústico 3: características mais vocálicas; Tipo Acústico 4: vocálico. FONTE: primária (2015).

A classificação foi organizada nos quatro grupos acústicos expostos anteriormente, formados pelos Tipos Acústicos 1, 2, 3 e 4. A partir daí, considerando os 33\% de produções do Tipo Acústico 1, que caracterizam a consoante nasal palatal; os $20 \%$ de produções do Tipo Acústico 2, com características mais consonantais; os 20\% de produções do Tipo Acústico 3, com características mais vocálicas; e os $27 \%$ de produções do Tipo Acústico 4, que caracterizam o som vocálico nasalizado, descreveremos as médias dos formantes desses tipos acústicos, conforme Tabelas 4 e 5 . Observe, nessas Tabelas, que os dados marcados com "--" não foram produzidos pelos locutores. 


\section{TABELA 4}

Médias do primeiro (FN1), segundo (FN2) e terceiro (FN3) formantes nasais dos tipos acústicos com características consonantais (Tipos Acústicos 1 e 2), por locutor e por número de dados $(\mathrm{n}=16)$.

\begin{tabular}{ccccc|cccc}
\hline & \multicolumn{4}{c}{ Formantes do Tipo Acústico 1 - [n] } & \multicolumn{4}{c}{ Formantes do Tipo Acústico 2 } \\
\hline & Média & Média & Média de & $\mathrm{N}^{\circ}$ de & Média de & Média de & Média de & $\mathrm{N}^{\circ}$ de \\
& de FN1 & de FN2 & FN3 & dados & FN1 & FN2 & FN3 & dados \\
\hline $\mathbf{L 1}$ & $203 \mathrm{~Hz}$ & $922 \mathrm{~Hz}$ & $2451 \mathrm{~Hz}$ & 2 & $240 \mathrm{~Hz}$ & $919 \mathrm{~Hz}$ & $2249 \mathrm{~Hz}$ & 1 \\
\hline $\mathbf{L 2}$ & $212 \mathrm{~Hz}$ & $1462 \mathrm{~Hz}$ & $2178 \mathrm{~Hz}$ & 8 & $208 \mathrm{~Hz}$ & $2028 \mathrm{~Hz}$ & $3046 \mathrm{~Hz}$ & 2 \\
\hline $\mathbf{L 3}$ & - & - & - & - & $227 \mathrm{~Hz}$ & $2094 \mathrm{~Hz}$ & $3641 \mathrm{~Hz}$ & 3 \\
\hline Média* & $\mathbf{2 1 0 ~ H z}$ & $\mathbf{1 3 5 4} \mathbf{H z}$ & $\mathbf{2 2 3 3} \mathbf{H z}$ & 10 & $\mathbf{2 1 9} \mathbf{H z}$ & $\mathbf{1 8 6 5 ~ H z}$ & $\mathbf{3 1 1 2} \mathbf{H z}$ & 6 \\
\hline
\end{tabular}

FONTE: primária (2015).

* As médias aqui apresentadas correspondem às produções de todos os locutores em cada tipo acústico.

\section{TABELA 5}

Médias do primeiro (F1), segundo (F2) e terceiro (F3) formantes dos tipos acústicos com características vocálicas (Tipos Acústicos 3 e 4$)$, por locutor e por número de dados $(n=14)$.

\begin{tabular}{ccccc|cccc}
\hline & \multicolumn{3}{c}{ Formantes do Tipo Acústico 3 } & \multicolumn{3}{c}{ Formantes do Tipo Acústico 4 - [j] } \\
\hline & $\begin{array}{c}\text { Média de } \\
\text { F1 }\end{array}$ & $\begin{array}{c}\text { Média de } \\
\text { F2 }\end{array}$ & $\begin{array}{c}\text { Média de } \\
\text { F3 }\end{array}$ & $\begin{array}{c}\mathrm{N}^{\circ} \text { de } \\
\text { dados }\end{array}$ & $\begin{array}{c}\text { Média de } \\
\text { F1 }\end{array}$ & $\begin{array}{c}\text { Média de } \\
\text { F2 }\end{array}$ & $\begin{array}{c}\text { Média } \\
\text { de F3 }\end{array}$ & $\begin{array}{c}\mathrm{N}^{\circ} \text { de } \\
\text { dados }\end{array}$ \\
\hline $\mathbf{L 1}$ & $236 \mathrm{~Hz}$ & $1618 \mathrm{~Hz}$ & $2897 \mathrm{~Hz}$ & 1 & $246 \mathrm{~Hz}$ & $2219 \mathrm{~Hz}$ & $3015 \mathrm{~Hz}$ & 6 \\
\hline $\mathbf{L 2}$ & - & - & - & - & - & - & - & - \\
\hline $\mathbf{L 3}$ & $215 \mathrm{~Hz}$ & $1599 \mathrm{~Hz}$ & $3068 \mathrm{~Hz}$ & 5 & $245 \mathrm{~Hz}$ & $2642 \mathrm{~Hz}$ & $3783 \mathrm{~Hz}$ & 2 \\
\hline Média* & $\mathbf{2 1 8} \mathbf{H z}$ & $\mathbf{1 6 0 2} \mathbf{H z}$ & $\mathbf{3 0 4 0 ~ H z}$ & 6 & $\mathbf{2 4 6 ~ H z}$ & $\mathbf{2 3 2 5} \mathbf{H z}$ & $\mathbf{3 2 0 7} \mathbf{H z}$ & 8 \\
\hline
\end{tabular}

FONTE: primária (2015).

* As médias aqui apresentadas correspondem às produções de todos os locutores em cada tipo acústico.

Observamos, pelas Tabelas 4 e 5, que as frequências dos formantes da consoante nasal palatal (Tipo Acústico 1) parecem ser caracterizadas por valores médios mais baixos para FN1 $(210 \mathrm{~Hz}), \mathrm{FN} 2$ $(1354 \mathrm{~Hz})$ e FN3 $(2233 \mathrm{~Hz})$ em relação aos demais tipos acústicos. No outro extremo da classificação, valores médios um pouco mais altos foram encontrados para o som vocálico nasalizado (Tipo Acústico 4), para F1 (246 Hz), F2 (2325 Hz) e F3 (3207 Hz), quando comparados aos outros tipos acústicos. 
Ainda, podemos salientar irregularidades do segundo formante nasal em torno de $1000 \mathrm{~Hz}$ com maior detectabilidade nos Tipos Acústicos 1, 2 e 3, tanto para consoantes nasais quanto para vogais nasalizadas, corroborando estudos anteriores.

Constatamos também, com base na Tabela 4, que dois locutores (L1 e L2) produziram a consoante nasal palatal (Tipo Acústico 1) em sua fala, e que todos os locutores produziram o Tipo Acústico 2, que apresenta características mais consonantais. Podemos inferir, portanto, que os falantes florianopolitanos podem apresentar produções consonantais (Tipo Acústico 1 e Tipo Acústico 2). Os dados da Tabela 5 demonstram que apenas um locutor (L2) não produziu sons nasais com características mais vocálicas (Tipo Acústico 3) nem o som vocálico nasalizado (Tipo Acústico 4). Esse resultado indica que nem todos os falantes de Florianópolis produzem sons nasais palatais com características vocálicas.

Esses dados evidenciam a variação que ocorre em uma mesma região geográfica, aliada a aspectos individuais, na produção desses sons nasais. Com esses resultados, respondemos à Questão 1 , ou seja, a consoante nasal palatal não apresenta as mesmas características acústicas em todas as suas produções.

Passaremos agora à análise dos dados aerodinâmicos na tentativa de responder às Questões 2 e 3.

\subsection{Análise aerodinâmica - configurações de curvas de fluxo aéreo nasal (FAN)}

Destacamos que, na análise aerodinâmica, mantivemos, para a transcrição fonética, o símbolo [n], independentemente do som apresentar características consonantais ou vocálicas. Primeiramente, realizamos uma classificação qualitativa dos traçados das curvas de fluxo aéreo nasal (FAN) com todos os dados registrados. Isso nos permitiu observar quatro configurações aerodinâmicas diferentes, a saber:

Configuração Aerodinâmica 1: a amplitude da curva de FAN progride lentamente (em rampa) a partir da vogal precedente $\left(\mathrm{V}_{1}\right)$ até atingir o pico máximo no som nasal $(\mathrm{Cn})$ e decresce lentamente para amplitude zero (linha preta pontilhada) que é atingida no final da vogal seguinte $\left(\mathrm{V}_{2}\right)$. 

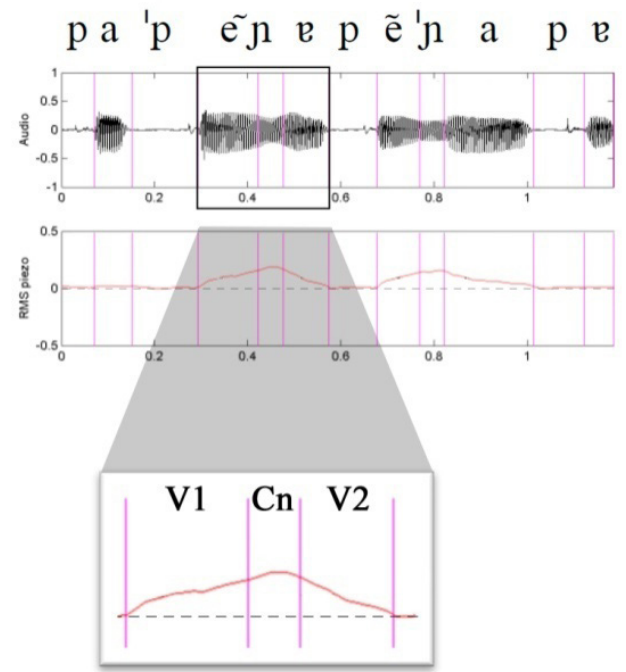

FIGURA 7 - Traçado da curva do fluxo aéreo nasal para a Configuração Aerodinâmica 1 nos logatomas [pa'pẽne pẽ'nape] (L3).

Em destaque, curva de FAN de [ẽje].

FONTE: primária (2015).

Configuração Aerodinâmica 2: a amplitude da curva de FAN progride rapidamente, subindo para uma amplitude máxima que é atingida ainda na vogal precedente $\left(\mathrm{V}_{1}\right)$, mantendo-se no som nasal $(\mathrm{Cn})$. A partir daí, a amplitude vai decrescendo até atingir amplitude zero (linha preta pontilhada) no final da vogal seguinte $\left(\mathrm{V}_{2}\right)$. 

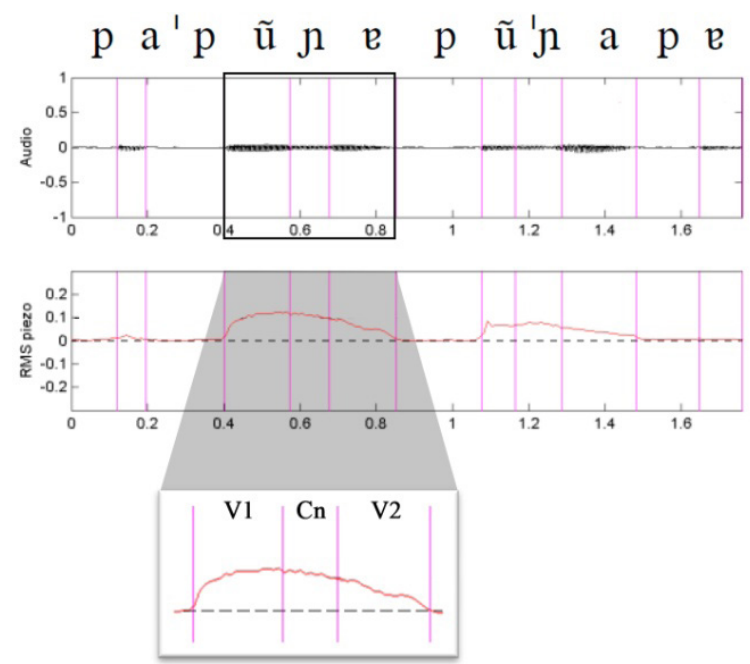

FIGURA 8 - Traçado do fluxo aéreo nasal para a Configuração Aerodinâmica 2 nos logatomas [pa'pũne pũ'nape] (L2). Em destaque, curva de FAN de [ũne].

FONTE: primária (2015).

Configuração Aerodinâmica 3: a amplitude da curva de FAN vai aumentando a partir da vogal precedente $\left(\mathrm{V}_{1}\right)$, mantendo-se praticamente em platô, até atingir amplitude máxima no som nasal $(\mathrm{Cn})$. Em seguida, a amplitude da curva de FAN vai decrescendo lentamente até atingir amplitude zero (linha preta pontilhada) no final da vogal seguinte $\left(\mathrm{V}_{2}\right)$. 

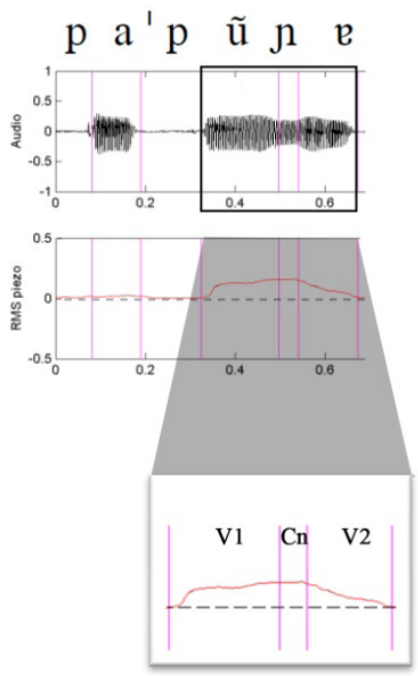

FIGURA 9 - Traçado do fluxo aéreo nasal para a Configuração Aerodinâmica 3 o logatoma [pa'pũne] (L3). Em destaque, curva de FAN de [ũje].

FONTE: primária (2015).

Configuração Aerodinâmica 4: a amplitude da curva de FAN aumenta rapidamente até atingir amplitude máxima na vogal precedente $\left(\mathrm{V}_{1}\right)$ e vai decrescendo lentamente até o final da vogal precedente $\left(\mathrm{V}_{1}\right)$, mantendo-se em platô no som nasal $(\mathrm{Cn})$. Em seguida, vai novamente decrescendo lentamente até atingir amplitude zero (linha preta pontilhada) no final da vogal seguinte $\left(\mathrm{V}_{2}\right)$. 

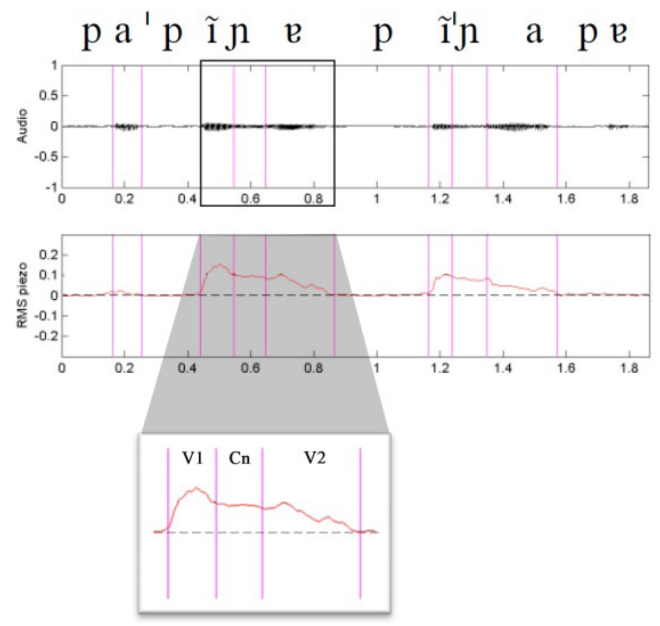

FIGURA 10 - Traçado do fluxo aéreo nasal para a Configuração Aerodinâmica 4 nos logatomas [pa'pĩne pí'nape] (L2). Em destaque, curva de FAN de [îne].

FONTE: primária (2015).

Identificamos 30\% de produções com a Configuração Aerodinâmica 1; 37\% de produções com a Configuração Aerodinâmica 2; 27\% de produções com a Configuração Aerodinâmica 3; e 6\% de emissões com a Configuração Aerodinâmica 4. Observamos diferenças em termos de amplitude máxima da curva de FAN entre as configurações descritas. Uma maior amplitude foi apresentada para a região da consoante nasal nas Configurações Aerodinâmicas 1 e 3, já a Configuração Aerodinâmica 2 apresentou amplitude semelhante na vogal precedente e na consoante nasal. A Configuração Aerodinâmica 4 mostrou maior amplitude da curva de FAN na região da vogal que precede a consoante.

A Configuração Aerodinâmica 4 foi caracterizada em apenas $6 \%$ dos dados (duas produções), quando a vogal [i] precedia a consoante nasal e quando eram emitidas pelo locutor 2 (L2). Diante desses aspectos muito específicos, como número de dados, produção diante de determinada vogal e somente por um locutor, optamos por não incluir a Configuração Aerodinâmica 4 nas análises subsequentes.

De modo geral, notamos certas regularidades nos traçados das curvas de FAN aqui observados para o som nasal intervocálico $(\mathrm{Cn})$, 
como, por exemplo, os das Configurações Aerodinâmicas 1, 2 e 4, que se assemelham a alguns contornos de curvas de FAN descritos para as vogais do francês por Amelot (2004).

Conforme os dados apresentados nesta seção, por meio da análise aerodinâmica qualitativa, conseguimos estabelecer configurações aerodinâmicas distintas de curvas de FAN advindas do piezo-elétrico para a consoante nasal palatal do PB, denominadas de Configurações Aerodinâmicas 1, 2, 3 e 4, respondendo assim parcialmente a Questão 2.

A fim de responder o segundo ponto da Questão 2, na seção a seguir, faremos uma comparação com as configurações aerodinâmicas das curvas de FAN, exibidas na Figura 7 (Configuração Aerodinâmica 1), na Figura 8 (Configuração Aerodinâmica 2) e na Figura 9 (Configuração Aerodinâmica 3), com as produções que foram classificadas em Tipo Acústico 1: consonantal [n], Tipo Acústico 2: características mais consonantais; Tipo Acústico 3: características mais vocálicas; e Tipo Acústico 4: vocálico.

\subsection{Análises dos tipos acústicos $x$ configurações aerodinâmicas}

Na Tabela 6, são contabilizadas as ocorrências das configurações aerodinâmicas de FAN (Config. 1, 2 e 3) por classificação com base nos tipos acústicos: consoante nasal palatal (Tipo Acústico 1); características mais consonantais (Tipo Acústico 2); características mais vocálicas (Tipo Acústico 3) e vogal nasalizada (Tipo Acústico 4).

\section{TABELA 6}

Número de ocorrências das configurações aerodinâmicas (Config. 1, 2 e 3) por tipos acústicos: Tipos Acústicos 1 e 2, com características consonantais;

e Tipos Acústicos 3 e 4, com características vocálicas $(n=28)$.

\begin{tabular}{c|c|c}
\hline \multicolumn{3}{c}{ Análise acústica e aerodinâmica } \\
\hline $\begin{array}{c}\text { Tipos Acústicos/ Configurações } \\
\text { Aerodinâmicas }\end{array}$ & $\begin{array}{c}\text { Tipos Acústicos 1 e 2 } \\
(\mathbf{n}=\mathbf{1 4})\end{array}$ & $\begin{array}{c}\text { Tipos Acústicos 3 e 4 } \\
(\mathbf{n}=\mathbf{1 4})\end{array}$ \\
\hline Config.1 $(\mathbf{n}=\mathbf{9})$ & $44 \%$ & $56 \%$ \\
\hline Config.2 $(\mathbf{n}=\mathbf{1 1})$ & $45 \%$ & $55 \%$ \\
\hline Config.3 $(\mathbf{n}=\mathbf{8})$ & $62,5 \%$ & $37,5 \%$ \\
\hline
\end{tabular}

FONTE: primária (2015). 
De acordo com o exposto na Tabela 6, analisamos os dados a fim de verificar se determinada configuração aerodinâmica tinha maior ocorrência em algum dos tipos acústicos. Ou seja, se uma configuração aerodinâmica apresentava características acústicas consonantais, juntando os Tipos Acústicos 1 e 2, que totalizavam 50\% das produções; ou características vocálicas, somando os Tipos Acústicos 3 e 4, que totalizavam $50 \%$ dos dados produzidos. Esses dados estão ilustrados no Gráfico 1.

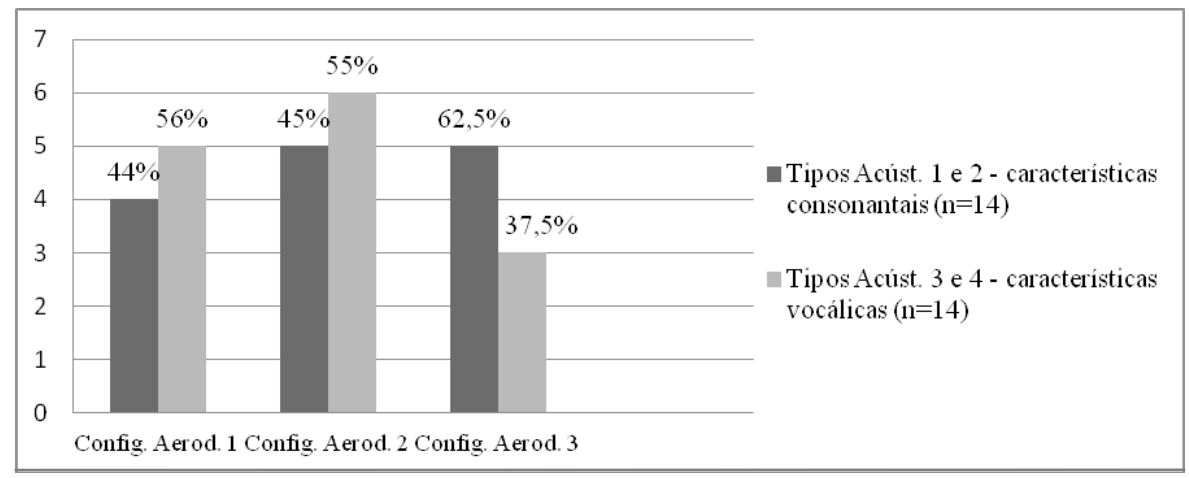

GRÁFICO 1 - Ocorrência dos tipos acústicos (Tipos Acústicos 1 e 2: características consonantais; Tipos Acústicos 3 e 4: características vocálicas) por configuração aerodinâmica (Configurações Aerodinâmicas 1,2 e 3) $(n=28)$.

FONTE: primária (2015).

De acordo com o Gráfico 1 e Tabela 6, observamos que os dados acústicos com características consonantais distribuem-se de forma equilibrada pelas três configurações aerodinâmicas, sendo o mesmo observado para os dados acústicos com características vocálicas, com uma restrição apenas para a Configuração Aerodinâmica 3.

Observamos, ainda, que as Configurações Aerodinâmicas 1 e 2 apresentam, respectivamente, ocorrência em 44\% e 45\% dos dados acústicos com características consonantais (Tipos Acústicos 1 e 2) e apresentam 56\% e 55\% com características vocálicas (Tipos Acústicos 3 e 4). Por sua vez, a Configuração Aerodinâmica 3 tem porcentagem mais evidente de ocorrência nos sons com características consonantais $(62,5 \%)$ do que nos sons com características vocálicas $(37,5 \%)$. 
Portanto, em resposta à Questão 2, não podemos afirmar, devido ao número de dados analisados e aos resultados obtidos, que as configurações aerodinâmicas distintas de curvas de FAN para a consoante nasal palatal estejam relacionadas às diferentes produções acústicas. Essa análise parece indicar que as características aerodinâmicas independem do tipo acústico, com características vocálicas ou consonantais, da consoante nasal palatal.

Consideramos ainda, na Seção 7.4, os fenômenos de coarticulação da nasalidade, observados nas curvas de FAN do som nasal e dos sons vocálicos adjacentes, considerando os diferentes tipos acústicos estabelecidos na análise acústica.

\subsection{Fenômenos de coarticulação da nasalidade}

Agora retomamos a classificação proposta das configurações de curvas aerodinâmicas e discutiremos a relação entre os fenômenos da nasalidade (antecipação, progressão, sincronização ou atraso), propostos por Basset et al. (2001) e a produção acústica dos sons com características consonantais (Tipos Acústicos 1 e 2) e com características vocálicas (Tipos Acústicos 3 e 4) com o objetivo de responder à Questão 3.

$\mathrm{Na}$ Figura 11, são exemplificados os fenômenos de antecipação e de progressão da nasalidade, referentes ao momento temporal de abaixamento do véu do palato, observando o som-alvo nasal em relação aos contextos vocálicos adjacentes. 
a)

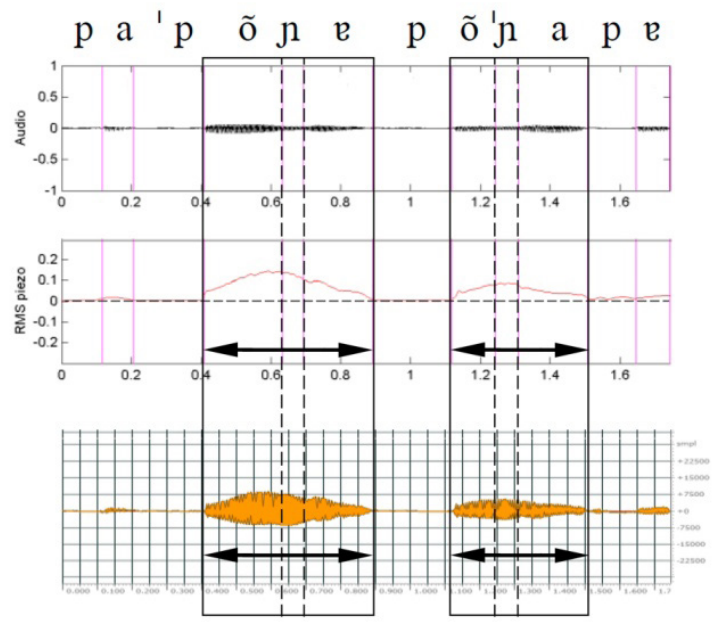

FIGURA 11 - Setas indicam os fenômenos da nasalidade: em (a), à esquerda (antecipação) e, em (b), à direita (progressão), a partir da consoante nasal palatal (entre pontilhados), nos logatomas [ра'рõne põ'nape] (L2). Em destaque, sequência sonora [õne ó'na].

FONTE: primária (2015).

O fenômeno de antecipação do abaixamento do véu do palato, conforme explica Vaissière (1995), implica uma reorganização do sistema motor com o seu abaixamento durante a vogal que precede a consoante nasal. No presente estudo, esse fenômeno de nasalidade regressiva ocorreu durante a vogal que precede os sons-alvo (Figura 11), corroborando estudos do PB que investigaram a vogal nasalizada, realizados por Moraes (2013) e por Mendonça e Seara (2015).

Segundo Vaissière (1995), o fenômeno de nasalização progressiva caracteriza-se quando a nasalidade se propaga à direita para outras vogais. Embora esses casos de nasalização progressiva sejam menos frequentes nas línguas, os dados obtidos no presente estudo apontam para a presença de propagação da nasalidade à direita da consoante nasal palatal e dos demais tipos acústicos em 100\% dos dados analisados (Figura 11). Esse resultado corrobora os encontrados por Moraes (2013) e por Mendonça e Seara (2015) para o PB. Em nossos dados, essa nasalidade progressiva se estendeu por toda a vogal vizinha em todos os dados analisados, 
tanto em vogais postônicas quanto tônicas. Dessa forma, o contexto de tonicidade não parece se mostrar um fator influenciador para a nasalidade progressiva nos logatomas investigados.

Conforme Basset et al. (2001), nas vogais do francês, pode ocorrer o início e o final sincrônico do FAN do som-alvo com o dado acústico. Em nossa pesquisa, os dados acústicos e aerodinâmicos não indicaram essa possibilidade de o início ou o término do FAN restringirem-se ao início ou final do som-alvo, conforme ilustrado na Figura 11.

Observamos, portanto, em resposta à Questão 3, os fenômenos relacionados ao comportamento do véu do palato que ocorrem durante a produção da consoante nasal palatal. A antecipação da curva de FAN está presente em todos os contextos vocálicos precedentes ao som nasal. Enquanto a progressão da curva de FAN do som nasal sobre a vogal seguinte também foi observada em todas as produções pelos três locutores. Constatamos, ainda, que a sincronização ou o atraso não foi verificado nos dados desta pesquisa.

Os resultados referentes à antecipação do abaixamento do véu do palato apresentaram diferentes curvas, uma que cobria toda a vogal precedente e outra que cobria apenas parte dessa vogal. Em virtude desse comportamento, outra análise qualitativa foi realizada a fim de verificarmos se essas diferentes curvas com início sincronizado ou não com o início da vogal precedente estavam relacionadas a configurações aerodinâmicas específicas.

Assim, dois casos distintos foram observados e estão demonstrados na Figura 12. No primeiro (a), quando a antecipação começava após o início da vogal precedente, foi chamada de antecipação parcial do FAN, pois mostrava menor antecipação sobre a vogal precedente. No segundo caso (b), quando a antecipação ocorria desde o início da vogal precedente, foi denominada de antecipação total, pois se estendia por toda a vogal precedente. 


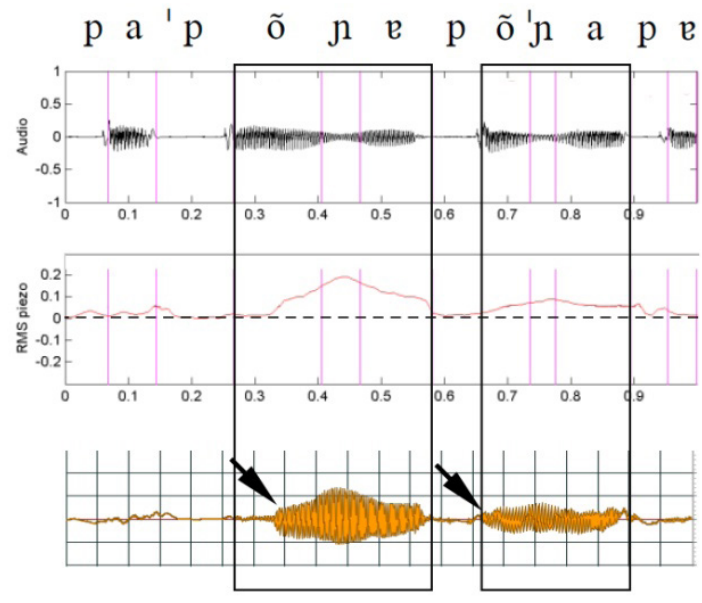

(a)

(b)

FIGURA 12 - Setas indicam: em (a), antecipação parcial no logatoma [pa'põne] e, em (b), antecipação total no logatoma [põ'nape] (L1). Em destaque, sequência sonora [õne õ'na].

FONTE: primária (2015).

Os dados referentes à análise dos fenômenos de antecipação total (Ant.Total) e antecipação parcial (Ant.Parcial) considerando as Configurações Aerodinâmicas 1, 2 e 3 estão expostos no Gráfico 2.

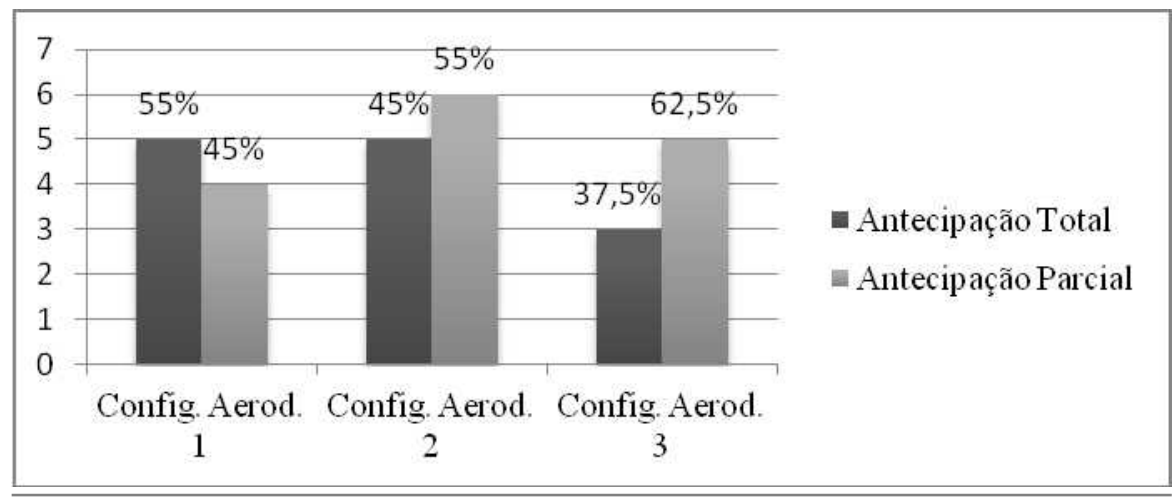

GRÁFICO 2 - Fenômeno de antecipação da nasalidade (Antecipação total e parcial) por configurações aerodinâmicas (Config. Aerod. 1, 2 e 3) (n=28).

FONTE: primária (2015). 
Pelo Gráfico 2, podemos observar que, na Configuração Aerodinâmica 1, o percentual de ocorrência de antecipação total (55\%) é levemente mais alto do que o de antecipação parcial (45\%), contrariamente ao que acontece com as Configurações Aerodinâmicas 2 e 3, que apresentam percentuais de ocorrência de antecipação parcial (55\% e 62,5\%, respectivamente) mais elevados do que os de antecipação total (45\% e 37,5\%, respectivamente). Esses resultados, embora não conclusivos, parecem indicar que pode haver um comportamento ligeiramente diferente quanto à antecipação (timing) da nasalização regressiva de acordo com o tipo de curva de FAN.

Os dados concernentes à ocorrência de antecipação da curva de FAN ratificam os achados de Mendonça e Seara (2015), para os quais já havia sido verificada essa tendência de antecipação, principalmente, para os dados de consoantes nasais palatais. Esses resultados também se mostraram diferentes dos apresentados em dados do francês, pois, enquanto, para o francês, a antecipação da curva de FAN sobre a vogal precedente está em torno de 51 a 54\% (BASSET et al. 2001), para os dados aqui pesquisados, ela se apresentou em 100\% dos casos, diferindo apenas no ponto de início (timing) da antecipação (total ou parcial).

\section{Conclusão}

A partir da investigação do detalhe fonético sobre dados de falantes de Florianópolis/SC, sugerimos o conjunto mais fidedigno de parâmetros para análise acústica da consoante nasal palatal do PB. Pelo espectrograma, observamos a energia (escurecimento e clareamento) e, pelas análises FFT e cepstral, observamos a amplitude das frequências mais altas. Dessa forma, constatamos que a consoante nasal palatal não apresenta uniformidade nas características acústicas, ocorrendo uma gradiência fônica nas produções, desde a consoante nasal palatal propriamente dita até a produção vocálica nasalizada.

Por meio da análise aerodinâmica, conseguimos estabelecer quatro configurações aerodinâmicas distintas de curvas de FAN para a consoante nasal palatal do PB. A relação entre tipos acústicos e configurações aerodinâmicas deve ser aprofundada a fim de auxiliar em uma possível direção na caracterização de sons nasais gradientes em futuras pesquisas, considerando o presente estudo como uma primeira contribuição acústicoaerodinâmica sobre a consoante nasal palatal do PB. 
Os resultados da análise aerodinâmica evidenciam a presença do fenômeno de antecipação da nasalidade na vogal que precede a consoante nasal palatal, bem como do fenômeno de nasalização progressiva, com propagação da nasalidade para a vogal seguinte, tanto em contexto átono (postônico) quanto tônico.

Concluímos, ainda, que a antecipação da nasalidade pode ocorrer de modo variado, temporalmente, na vogal precedente: desde seu início (antecipação total) ou começar um pouco depois do seu início (antecipação parcial). Esse pode ser um aspecto aerodinâmico a ser melhor investigado para sinalizar uma produção mais consonantal ou mais vocálica.

A partir dos resultados obtidos, podemos dizer que o uso do captador piezo-elétrico permitiu descrever configurações e interagir com os dados acústicos no estudo de aspectos temporais e qualitativos da nasalidade do PB, avançando no entendimento sobre a consoante nasal palatal.

\section{Agradecimentos}

À equipe de pesquisadores do Laboratoire de Phonétique et Phonologie, da Université Paris III - Sorbonne Nouvelle, em Paris/França.

Ao CNPQ pela bolsa de produtividade.

Ao Programa de Bolsas Universitárias de Santa Catarina - UNIEDU/ FUMDES da Diretoria de Educação Superior (DIES) da Secretaria de Estado da Educação (SED).

Aos pareceristas anônimos desta Revista pela leitura rigorosa e pelos comentários ao texto original que certamente contribuíram para uma versão mais adequada do artigo. Salientamos, no entanto, que as inadequações remanescentes são de nossa inteira responsabilidade.

\section{Referências}

ALTMANN, E. B. C. Anatomia e fisiologia do esfíncter velofaríngico. In: ALTMANN, E. B. C. (Org.). Fissuras Labiopalatinas. São Paulo: Pró-Fono, 2007. p. 133-153.

AMELOT, A. Étude aérodynamique, fibroscopique, acoustique et perceptive des voyelles nasales du français. 2004. 203f. Tese (Doutorado) - Université Paris III - Sorbonne Nouvelle, Paris, 2004. 
BASSET, P.; AMELOT, A.; CREVIER-BUCHMAN, L. Etude multiparamétrique des consonnes nasales du français: prise de données simultanées aérodynamiques et fibroscopiques. Parole, 2007. halshs-00139540, version 1, 2 Apr., 2007.

BASSET, P.; AMELOT, A.; VAISSIÈRE, J.; ROUBEAU, B. Nasal airflow in French Spontaneous Speech. Journal of the International Phonetic Association, v.31, n.1, p. 87-100, 2001.https://doi.org/10.1017/ S0025100301001074.

BELL-BERTI, F. Understanding Velic Motor Control: Studies of Segmental Context. In: HUFFMAN, M. K.; KRAKOW, R (Ed.). Nasals, Nasalization and the Velum. San Diego: Academic Press, 1993. p. 63-85. https://doi.org/10.1016/B978-0-12-360380-7.50007-7.

BOERSMA, P.; WEENINK, D. Praat: doing phonetics by computer. Amsterdam: Universidade de Amsterdam. Disponível em: $<$ http://www. praat.org >. Acesso em: 2011.

BRKAN, A.; AMELOT, A.; PILLOT-LOISEAU, C. Utilisation d'un accéléromètre piézoélectrique pour l'étude de la nasalité du Français Langue Etrangère. Actes de la conférence conjointe JEP-TALN-RECITAL, v. 1, p. 689-696, 2012.

CROWLEY, T.; BOWERN, C. An introduction to historical linguistics. 4 ed. New York: Oxford University press, 2010.

FANT, G. Nasal Sounds and Nasalization In: Acoustical Theory of Speech Production. The Hague: Mouton, 1960. p. 140-161.

FERNANDES, J. Segurança nas vibrações sobre o corpo humano. Disponível em: $<$ http://wwwp.feb.unesp.br/jcandido/>. Acesso em: nov. 2014.

FREITAS, G. C. M. Sobre a aquisição das plosivas e nasais. In: LAMPRECHT, R. R. et al. Aquisição fonológica da português: perfil de desenvolvimento e subsídios para terapia. Porto Alegre: Artmed, 2004. p. 73-82. PMid:15367772.

GAMBA, P. A. A consoante nasal palatal no português brasileiro. 2011. 58f. Trabalho de conclusão de curso (Bacharelado em Letras) Universidade Federal de Santa Catarina, 2011. 
GAMBA, P. A. As soantes palatais no português: uma caracterização fonético-fonológica. 2014. 144f. Dissertação (Mestrado) - Universidade Federal de Santa Catarina, 2014.

HOUSE, A.; STEVENS, K. Analog studies of nasal consonants. Journal of Speech and Hearing Disorders, v. 22, p. 190-204, 1957. https://doi. org/10.1044/jshd.2202.190. PMid:13429662.

KELLER, E. Fundamentals of phonetic Science. In: KELLER, E. (Ed.). Fundamentals of speech synthesis and speech recognition. New York: John Wiley \& Sons, 1999. p. 5-21.

MEDEIROS, B. R.; D’IMPERIO, M.; ESPESSER, R. O apêndice nasal: dados aerodinâmicos e duracionais. Revista do GEL, São Paulo, v. 5, n. 2, p. 123-138, 2008.

MENDONÇA, C. S. I. de; SEARA, I. C. Análise aerodinâmica da nasalidade coarticulatória no falar florianopolitano. Revista Domínios de Linguagem, v.9, n.5, p. 83-104, 2015. https://doi.org/10.14393/ dle-v9n5a2015-5.

MORAES, J. A. Produção e percepção das vogais nasais. In: CASTILHO, A. T. (Coord.); ABAURRE, M. B. M. M(Org.). Gramática do português culto falado no Brasil - volume VII: a construção fonológica da palavra. São Paulo: Contexto, 2013. p. 95-112.

SEARA, I. C. Estudo acústico-perceptual da nasalidade das vogais do português brasileiro Tese (Doutorado em Linguística) - Universidade Federal de Santa Catarina, Florianópolis (SC), 2000.

SEARA, I. C.; BERRI, A. R. Vogais nasais do francês: observações sobre falantes nativos e aprendizes de FLE. Fórum Linguístico, Florianópolis, v.6. n.1, p. 91-104, jan.-jun., 2009. https://doi.org/10.5007/19848412.2009v6n1p91.

SEARA, I. C.; NUNES, V. G.; LAZZAROTTO-VOLCÃO, C. Fonética e fonologia do português brasileiro. São Paulo: Contexto, 2015.

SILVA, T. C. Fonética e fonologia do português: roteiro de estudos e guia de exercícios. 10. ed. São Paulo: Contexto, 2010.

SOUSA, E. Para a caracterização fonético-acústica da nasalidade no Português do Brasil. 1994. 180f. Dissertação (Mestrado) - Universidade Estadual de Campinas, 1994. 
VAISSIÈRE, J. Nasalité et phonétique, Le voile du palais et la parole. In: Conférence Tutorielle Invitée, Colloque sur le voile pathologique, Mai. 1995, Lyon, publié par la Société Française de Phoniatrie de la Société d'Acoustique, 1996.

VAISSIÈRE, J.; HONDA, K.; AMELOT, A.; MAEDA, S.H.; CREVIERBUCHMAN, L. Multisensor platform for speech physiology research in a phonetics laboratory. The Journal of the Phonetic Society of Japan, v.14, n.2, p. 65-78, 2010. 